\title{
A Longitudinal Study Of Generic Alcohol And Tobacco Cues In Daytime Soap Opera Programs: Fall, 1986, 1991, And 2001
}

Betty J. Diener, (E-mail: bdiener@mail.barry.edu), Barry University

\begin{abstract}
A longitudinal study was conducted to determine the frequency and context of generic alcohol and tobacco cues in daytime television soap opera programs broadcast in fall, 1986, 1991, and 2001. A content analysis of these programs showed that alcohol cues occurred significantly more frequently than tobacco cues. The alcohol cues occurred with significantly increasing frequency in $1991 \mathrm{vs.}$ 1986, and then again in 2001 vs. 1991. Although the alcohol cues were generic (unbranded), in "appropriate" settings, and neither actively consumed nor directly related to storylines, their significantly increasing use could still be of concern.
\end{abstract}

\section{INTRODUCTION}

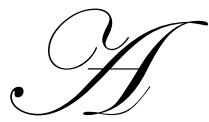

content analysis was conducted of daytime television soap opera programs broadcast in 2001 that was intended to update an earlier study of the frequency and context of two socially sensitive product categories - alcohol and tobacco - that was first reported in the Journal of Public and Policy \& Marketing (Diener 1993).

The purpose of this study is to provide further longitudinal evidence of the frequency and context of cues, to identify the manner in which they were portrayed, and to see if the frequency of generic (unbranded) alcohol cues continued to increase significantly, and if the frequency of tobacco cues continued to be negligible.

The product categories of alcohol and tobacco continue to be relevant because of the public policy concerns about their consumption levels (particularly by young people), the costs to society related to their use, and the portrayal of these products not only in paid advertising but also in program content.

Over 10 million American teens (29\% of those age 12 thru 20) are considered to be regular users of alcohol. (U.S. Dept. of Health and Human Services 2006). The three leading causes of death for 15-24 year olds are car crashes, homicides, and suicides - alcohol is a leading factor for all three (Focus Adolescent Services). Total alcohol-related health care costs are $\$ 22.5$ billion annually (Rice, 1999); roughly $25-40 \%$ of people in general hospital beds at any time are being treated for complications of alcoholism. Total economic costs of alcohol abuse in 1994 were estimated to be $\$ 175.9$ billion (Center on Addiction and Substance Abuse 1994).

Health care costs from smoking are over $\$ 89$ billion each year. Tobacco use is blamed for 1 in 5 deaths each year. Over 1 in 5 high school students smoke (National Youth Risk Behavior Survey, 2003).

Cigarette advertising has been banned from broadcast advertising for many years; health warnings are already required on both cigarette and alcohol packaging.

In addition, the FTC evaluated an important alcohol industry initiative that involved voluntary self-regulatory codes intended to prevent alcohol advertising and marketing that appealed to underage consumers. They concluded that self-regulation is a realistic, responsive and responsible approach to many of the issues raised by underage drinking. The industry voluntarily seeks to minimize the extent to which underage consumers are exposed to and 
attracted by alcohol advertising by employing self-regulatory codes. The Commission concluded that for the most part, members of the industry complied with the current standards set by the voluntary advertising codes, which prohibit blatant appeals to young audiences and advertising in venues where most of the audience is under the legal drinking age. In addition, many individual companies follow their own internal standards that exceed code requirements when they are deciding what their ads should say and where they should be placed (FTC, 1999). Nothing has ever been said, however, about visual cues implanted in programming, simply about brand-identified advertising and marketing.

One purpose of this longitudinal research, extending fifteen years, from 1986 to 2001, is to help inform those debating about the portrayal of alcohol and tobacco in television programming by describing the frequency and context with which cues for these products are portrayed in one area of television programming - daytime soap operas. Daytime soap operas were selected because of individuals that watch regularly and over long periods of time, and because of the demographics of the population who watch them.

In fall, 1986 and fall, 1991, regular viewers of each of the eight major soap operas ranged from 4-8 million. This dropped in 2001, among the seven of those still on-air, to 3-4.7 million. 20 million total viewers were estimated to be regular soap opera viewers on a daily basis in 1991 - this figure increased to 30 million in 2001 (A.C.Nielsen).

Table 1 shows the daytime soap operas used in this research, the networks on which they appeared, and their ratings, share, and daytime rank in each of the years studied.

\section{Table 1}

Ratings Of Daytime Regularly Scheduled Soap Opera Programs September - December

\begin{tabular}{lccc} 
& $\begin{array}{c}\text { Ratings } \\
\text { Fall 1986 }\end{array}$ & $\begin{array}{c}\text { Ratings } \\
\text { Fall 1991 }\end{array}$ & Ratings \\
Fall 2001 & \\
Network/Program & & & 3.4 \\
ABC General Hospital & 8.2 & 5.6 & 4.7 \\
CBS Young \& Restless & 7.8 & 8.1 & 3.2 \\
ABC One Life to Live & 7.1 & 5.1 & 3.2 \\
ABC All My Children & 6.9 & 6.4 & 3.5 \\
NBC Days of Our Lives & 6.8 & 5.3 & 3 \\
CBS As the World Turns & 6.8 & 5.8 & \\
CBS Guiding Light & 6.3 & 5.6 & \\
NBC Santa Barbara & 4.2 & 3 & \\
\hline
\end{tabular}

Source: A.C. Nielsen, January 1987, 1992, 2002

Note: Each daytime ratings point represented approximately 1 million

viewers in 1986 and 1.2 million viewers in 1991 and in 2001

Viewership of daytime soap operas is quite extensive. In a study conducted in 2000, it was reported that onethird of all respondents age 18 and over indicated that they watch daytime soaps a few times a month; $19 \%$ are regular viewers, watching two or more times per week. Further, $25 \%$ of women were regular viewers, vs. $12 \%$ of males. $31 \%$ of blacks, $25 \%$ of Hispanics, and $17 \%$ of whites were regular viewers. The age analysis showed that $25 \%$ of those $18-29,16 \%$ of those $30-64$, and $20 \%$ of those 65 or over were regular users. With regard to income,. $26 \%$ of those who completed high school or less were regular users, compared to $15 \%$ of those with college educations. And $29 \%$ of those with incomes under $\$ 20,000,20 \%$ with incomes $\$ 20-50,000$, and $12 \%$ of those with incomes over $\$ 50,000$ were regular viewers. The conclusion, then is that soap opera viewers are disproportionally women, younger or senior, blacks or Hispanics, less well educated, and lower income (Pollard, 2000). 
Another reason for studying the frequency and context of generic alcohol cues is that there is so much concern about their possible impact on consumer behavior, and, at the same time, so little agreement about that impact. There is little reporting on branded product placements about alcoholic products, nor is there anything about unbranded or generic placements. The Center for the Study of Commercialism (Heitsmith, 1992) expressed concerns about branded product placement of alcoholic products such as beer. Commercial Alert, in 2003, filed complaints with the Federal Communications Commission and the Federal Trade Commission over branded product placements embedded as beer company signs on the set of The Best Damn Sports Show Period. (Bauder, 2003). Commercial Alert's Gary Ruskin said "TV stations are turning programs into infomercials, but viewers are often not aware that these ads are ads. That's totally unfair!”.

A literature search identified only one study done on the quantity of branded product placements/cues, none on the quantity of unbranded product placement/cues, and none on the effects of cues or product placements in television programming, for either branded or generic products.

With regard to the possible impact of cues, one has to go back to the 1970's to find research that says that individuals do screen and process the cues they see and hear, but they cannot be stimulated to do something they don't inherently want to do. Thus, no one could be persuaded to drink alcohol if they don't already want to do so. (Comstock, 1977).

In addition, because sponsored advertising often has difficulty in effecting consumer purchasing, alcohol or tobacco cues could also be expected to have similar difficulty. Though an audience might absorb pictorial cues, they would probably still be without an overt sense of what is being seen (Krugman, 1988). And there is little evidence that any effects would be anything other than brief, of small magnitude, subtle, and easily nullified by more open and overt communications (Moore 1982).

There is an opposite point of view, however, that holds that cues or product placements might be effective if "unconscious learning" took place. This is believed to occur when a television viewer's defensive or screening barriers are lowered, there are high levels of constant repetitious behavior, and the viewer doesn't process a cue or message but rather puts it in the back of his or her mind into "long term memory" (Krugman, 1965). Thus the memory of a liquor decanter or a pack of cigarettes would not be actively processed, but learned unconsciously without awareness or cognitive learning and placed in the back of the mind. Because the message is suggestive rather than commanding, it would have to be seen numerous times over a long period to be effective. Of concern here is that these are exactly the conditions of exposure and continuity found in soap opera viewing.

A reason then for concern over the use of alcohol and tobacco cues in daytime soap operas is that soap opera viewers, who are traditionally low-income women, teens, and elderly, view their favorite shows with a great frequency and continuity over years, and identify deeply with the characters and their problems. They are known to be deeply involved in story lines, having to concentrate because of the complexity and the number of story lines in each program (Rose 1979). There is intense and persistent loyalty from the viewers who continue to watch favorite shows over extensive periods of their lives with growing depth of involvement (Kielwasser 1989).

Also in support of this concern is another stream of communications research that holds that television is a symbolic environment that is extremely persuasive in forming cultural values (Gerbner et al. 1982), particularly among those viewers of television who have less education, lower mobility, and lower aspirations (Gerbner, 1973). Heavy viewers in particular use scripts that television offers to form expectations about life-styles. In addition, social learning theory suggests that repeated exposure to modeled behavior can result in behavioral change (Bandura 1971, 1977).

If television is believed to be persuasive in forming cultural values, it might possibly create a world in which drinking or smoking looks attractive and viewers can equate alcohol with success (Diamond 1988) If drinkers, for example, look glamorous or wealthy, this might lead a viewer to form an attitude regarding successful life-styles that could contribute to the normalization of drinking in American life (Wallack 1987). 
A third, older but still relevant, point of view is that television viewing might have some (difficult to measure) effect on viewers, depending on:

- $\quad$ the level of interest in what is being viewed;

- the degree to which the viewer identifies with the characters and the degree to which the show is liked (Clancy 1971);

- $\quad$ the amount of time spent watching and the degree of repetition in what they're seeing (Greenberg and Suttoni 1973); and

- $\quad$ whether the viewer tends, because of a low level of self-confidence, to weight more heavily perceptual evidence coming from respected sources and if there is nothing to inhibit a viewer from engaging in selfprotective cognitive processing (Hovland and Janis 1959).

In summary, there is a possibility that those who have watched soap operas over a number of years could possibly have had a system of reality created for them influencing their values, behavior, and life-style. They may even be unconsciously be absorbing cues about drinking and smoking - for example: that having decanters in a living room or drinks in a restaurant is a sign of success.

\section{HYPOTHESES}

When the first part of the longitudinal study was conducted, it was hypothesized that, given the similar kind of societal concerns about tobacco and alcohol, that the frequency with which cues for these products were portrayed would be similar. It was also hypothesized then that, given continued and increased levels of societal concerns, the frequency of cues for these products would decline over time.

When the second part of the longitudinal study was conducted, it had already been shown that there were numerous and increasing cues for alcohol but very infrequent cues for smoking. The second part of the study then was conducted to see whether these trends continued.

\section{METHODOLOGY}

Content analysis was performed on daytime soap opera programming that had been videotaped during August-October 1986 (40 hours), 1991 (40 hours) and 2001 (35 hours since one of the soap operas had gone off the air). The August-October period was selected in 1986 because it was believed to be a theme-neutral period - no weddings, graduations, Christmas parties, etc.. It was used in 1991 and 2000 for consistency.

Five one-hour episodes were taped for each soap opera each year, for a total of 40 hours in 1986 and 1991 and 35 hours in 2001. For each soap opera, one episode per week was taped, each on a different day of the week.

Coding of the 1986 and 1991 tapes was performed in 1992 by 16 members of an undergraduate class; coding of the 2001 tapes was performed in 2003 by members of a graduate class. Coding instructions were developed on the basis of previous experience with content analysis of soap operas for a separate project. The coding was done on a scene basis, and included identification of the location of the scene, individuals present and what they were doing, topics of discussion, and whether there was conflict (argument, fight, accusation) in the scene. Each scene was also coded for the presence or absence of alcohol and tobacco. If either were present, the coders noted the type, whether it was being consumed or not, or whether it was simply placed in the scene without direct involvement with the characters.

Training of the coders was done over two sessions where they practice coded tapes similar to the ones they would be coding for the formal analysis. Students coded in pairs and each member independently viewed and coded the tapes...they then met to compare their coding, noting the number and types of their disagreements. They then resolved their coding disagreements by reviewing the tapes together, jointly observing frames until both agreed on the total coding for each scene. Only four disagreements could not be resolved by this process - each involved a question 
of whether alcohol was present, since the liquid seen in a glass could be another beverage such as iced tea. In these cases the liquid was not coded as alcohol.

The use of student coders raises the possibility of limitations in the findings of the content analysis. The coding design was therefore specifically evaluated against Kassarjian's (1977) directives regarding objectivity, systemization, quantification, sampling and reliability. Coding done in 1992 (for 1986 and 1991 tapes) was also subjected to Perreault and Leigh's 1989 method of measuring interjudge reliability, the level and adequacy of intercoder reliability were reviewed, and the causes of disagreements were identified.

The estimates of interjudge reliability were high for the presence of alcohol (.949) and tobacco (.994), and for the type of alcohol and whether it was consumed (.963) This is due primarily due to the dichotomous nature of many of the coding categories. For example, alcohol and tobacco cues were easily seen to be present or not. In addition the coding categories were as exhaustive as possible so that the coding would be clerical in nature rather than judgmental. Coders were found to code the scenes with virtually the same results, even when coding independently of each other. The interjudge reliability estimate for the type and consumption of tobacco was lower (.818) due to a combination of the small number of observations of tobacco cues and a question of whether a particular tobacco cue was a cigarette or cigarillo. Because of the high degrees of reliability, these tests were not repeated in 2003, based on the assumption that the training and the structure of the coding were identical.

The coding for the presence or absence of alcohol and tobacco was especially critical. Alcohol was defined as hard liquor, liqueurs, champagne, wine and beer. Tobacco was defined as cigarettes, cigars and pipes. For alcohol or tobacco to be coded as "present" there had to be a visual or verbal reference to cigarettes, smoking, drinks, drinking, etc. They could be present in the scene or be in the process of consumption. Products were also coded as branded or unbranded. None of the cues, however, for any of the periods studied, were branded.

Examples of verbal references could include: "Would you like a cigarette?" "Do you want to meet for a drink later?" Examples of visual references could include filled decanter sets or liquor bottles used as scenery props, filled or partially filled alcoholic drink glasses on a table, being held, or being consumed, cigarettes being smoked by characters.

\section{FINDINGS}

The frequency with which alcohol and tobacco cues were found, by year, appears in Table 2 .

\begin{tabular}{|c|c|c|c|}
\hline \multicolumn{4}{|c|}{$\begin{array}{c}\text { Table } 2 \\
\text { Frequency Of Alcohol Or Tobacco Cues In Daytime Soap Opera Programming: } \\
\text { Fall 1986, Fall 1991, Fall 2001 }\end{array}$} \\
\hline & 1986 & 1991 & 2001 \\
\hline Number of Soap Operas Taped & 8 & 8 & 7 \\
\hline Number of Episodes per Soap Opera & 5 & 5 & 5 \\
\hline Total Number of Episodes Taped & 40 & 40 & 35 \\
\hline Total Number of Scenes Coded & 1,066 & 1,064 & ,536 \\
\hline \multicolumn{4}{|l|}{ Scenes Including: } \\
\hline - Alcohol/Drinking & 144 & 208 & 243 \\
\hline Alcohol Cues as \% Scenes & $14 \%$ & $20 \%$ & $16 \%$ \\
\hline - Tobacco/Smoking & 4 & 11 & 5 \\
\hline \multicolumn{4}{|l|}{ Number of Cues Related to Story Line } \\
\hline - Alcohol/Drinking & 2 & 6 & 5 \\
\hline - Tobacco/Smoking & 0 & 0 & 0 \\
\hline
\end{tabular}


As was true in the earlier analysis, the frequency - the proportion of scenes - in which tobacco and alcohol cues were seen was widely different for tobacco and alcohol. The number of scenes in which tobacco was seen continued to be marginal in 2001 in only 5 of 1,536 scenes. On the other hand, the number of scenes in which alcohol cues were seen were substantial in number, with sightings in the absolute number of scenes increasing, from 144 out of 1,066 scenes in 1986 (13\%), to 208 out of 1064 scenes in 1991 (20\%), to 243 out of 1536 scenes in 2001 (16\%). The difference is significant beyond the .001 level for all the years. Thus, it was found that generic cues for tobacco placed in soap operas continue to have little frequency. Conversely, the portrayal of generic alcohol cues in soap operas continue at a significant level.

Because of the observed level of alcohol cues in each period studied, further tabulations of the codings were compiled in order to see what types of alcohol were being included, the locations at which it was present, whether the alcohol was being consumed or was about to be consumed, and whether conflict was occurring in the presence of alcohol cues. The data was analyzed in this section, but no preconceived hypotheses were used.

Though the frequency of scenes that included alcohol cues increased in each of the periods studied, the distribution of the types of alcohol, locations, and consumption of alcohol remained similar in each of the three periods studied. (Table 3)

\begin{tabular}{|c|c|c|c|}
\hline $\begin{array}{c}\text { Table } 3 \\
\text { 1986, 1991, } 2001 \\
\text { Context Analysis of Alcohol Cues }\end{array}$ & & & \\
\hline YEAR & 1986 & 1991 & 2001 \\
\hline Type of Alcohol Cue: & & & \\
\hline Liquor & $49 \%$ & $51 \%$ & $49 \%$ \\
\hline Bottle/decanter & $31 \%$ & $28 \%$ & $30 \%$ \\
\hline Glass/drink & $15 \%$ & $22 \%$ & $18 \%$ \\
\hline Other & $3 \%$ & $1 \%$ & $1 \%$ \\
\hline Wine & $20 \%$ & $23 \%$ & $22 \%$ \\
\hline Champagne & $14 \%$ & $13 \%$ & $4 \%$ \\
\hline Beer & $1 \%$ & $6 \%$ & $5 \%$ \\
\hline Combination & $16 \%$ & $7 \%$ & $20 \%$ \\
\hline Total Type & $100 \%$ & $100 \%$ & $100 \%$ \\
\hline Location: & \multirow{8}{*}{$\begin{array}{c}51 \% \\
38 \% \\
36 \% \\
2 \% \\
5 \% \\
4 \% \\
2 \% \\
\end{array}$} & \multirow{8}{*}{$\begin{array}{c}54 \% \\
32 \% \\
28 \% \\
4 \% \\
6 \% \\
6 \% \\
2 \% \\
\end{array}$} & \multirow{8}{*}{$\begin{array}{c}51 \% \\
37 \% \\
38 \% \\
0 \% \\
7 \% \\
2 \% \\
2 \%\end{array}$} \\
\hline Bar/Rest/Club & & & \\
\hline Home & & & \\
\hline living area & & & \\
\hline bedroom & & & \\
\hline Office & & & \\
\hline Hotel & & & \\
\hline Other & & & \\
\hline Total Location & $100 \%$ & $100 \%$ & $100 \%$ \\
\hline Alcohol Being Consumed/About to be Consumed & \multirow{3}{*}{$\begin{array}{l}41 \% \\
59 \% \\
\end{array}$} & \multirow{3}{*}{$\begin{array}{l}37 \% \\
63 \% \\
\end{array}$} & \multirow{4}{*}{$\begin{array}{l}51 \% \\
49 \% \\
100 \%\end{array}$} \\
\hline Yes & & & \\
\hline No & & & \\
\hline Total Consumed/Held & $100 \%$ & $100 \%$ & \\
\hline Conflict Present with Alcohol & \multirow{3}{*}{$\begin{array}{l}32 \% \\
68 \%\end{array}$} & \multirow{3}{*}{$\begin{array}{l}28 \% \\
75 \%\end{array}$} & \multirow{3}{*}{$\begin{array}{c}0 \% \\
100 \%\end{array}$} \\
\hline Yes & & & \\
\hline No & & & \\
\hline
\end{tabular}


Roughly half the alcohol cues showed hard liquor, either in mixed drinks or in decanter sets. Another third showed wine or champagne. Almost no generic alcohol cues were of beer. Thus, for all three periods studied, the alcohol cues continued to be of more upscale types of alcohol (decanter sets in living rooms, drinks in a nice restaurant) than would be true of the types of alcohol likely used by lower-income viewers of the soap operas.

Furthermore, alcohol cues continued to be associated with moderate consumption behavior in "appropriate" locations. The research in 2001 found that $88 \%$ of the total alcohol cues were found in living rooms and bars/restaurants (rather than bedrooms and offices), virtually the same as in 1986 and 1991 (87\%). The consumption of alcohol increased in 2001 to 51\% of the scenes, up from $41 \%$ in 1986 and 37\% in 1991. And none of the alcohol cues in 2001 were in scenes with conflict in the story lines characters were just speaking and were not fighting or in conflict.

Therefore, for the most part, the alcohol cues, although increasingly seen, were generic and used in appropriate settings; the alcohol was actively consumed in only about half the scenes, and the cues were not in scenes associated with conflict situations.

\section{IMPLICATIONS AND PUBLIC POLICY ISSUES}

At the time this research was first reported (using the 1986 and 1991 data), alcohol cues on daytime soap operas, though found to be occurring more frequently than cues for tobacco and increasingly often, were also associated with moderate consumption behavior in the background of the programs and at appropriate locations. The question was asked then of why should anyone be concerned if decanter sets appeared in living rooms or if alcoholic drinks were seen on restaurant tables?

These questions continue to be asked. But now there is evidence that soap operas have been including these cues in an increased number of scenes and the portrayal of alcohol cues has continued and even increased over 15 years!

The reason for concern also continues to be that the research is inconclusive and often contradictory on the issue of impact. One stream of research supports the position that product cues would probably not have any meaningful impact on television viewers, particularly if they are not in the forefront of the program, not integrated into story lines, and not branded where the brand labels are easily identified. Other research supports the position that produce cues might have an impact. Proponents here would believe that television is so persuasive in forming cultural values that any portrayal of alcohol, even as normal, appropriate and innocuous, creates a world in which drinking looks attractive and is a part of everyday life.

Certainly anti-alcohol activists would not want alcohol consumption to be portrayed as a part of everyday life and would be concerned to know that alcohol cues associated with "normal" or "success" situations are being placed in programming that reaches large numbers of high school and college students, not to mention minorities, retirees, and young women with low household income

\section{FURTHER RESEARCH}

The research described in this study describes, albeit at 3 points over 15 years, describes only the frequency and context of alcohol and tobacco cues in daytime soap opera programming. It does not make any inferences about the actual effects of such cues. The sampling of the shows was also limited in quantity and seasonality. These limitations could be further explored in future research so that the impacts of these unbranded alcohol cues could be better understood. 


\section{REFERENCES}

1. Bandura, Albert (1971), Social Learning Theory. New York: General Learning Press.

2. _ (1977), Social Learning Theory, $2^{\text {nd }}$ ed., Englewood Cliffs, N.J., Prentice-Hall

3. Bauder, David, Product Placement on TV Comes Under Scrutiny. Miami Herald. Oct. 27, 2003, p.16.

4. Campaign for Tobacco-Free Kids. National Youth Risk Behavior Survey, 2003.

5. Center on Addiction and Substance Abuse, Columbia University, The Cost of Substance Abuse to the American Health Care System, Report 1, 1994.

6. Clancy, Kevin J. and David M. Kweskin (1971), TV Commercial Recall Correlates, Journal of Advertising Research, 11 (2), 18-20.

7. Comstock, George (1977), Types of Portrayal and Aggressive Behavior, Journal of Communications, 27, (3), 189-98.

8. $\quad$ Diamond, Bill (1988), Is TV All Bad?, Seventeen, (November), 87.

9. Diener, Betty J., The Frequency and Context of Alcohol and Tobacco Cues in Daytime Soap Opera Programs: Fall, 1986 and Fall, 1991, Journal of Public Policy and Marketing, Vol. 12 (2), Fall 1993, pp.252257.

10. Federal Trade Commission, Regulation in the Alcohol Industry, September, 1999.

11. Focus Adolescent Services. http://www.focusas.com/Alcohol.html.

12. Gerbner, George (1973), Teacher Image in Mass Culture: Symbolic Functions in the Hidden Curriculum, Communications Technology and Social Policy,_George Gerbner et all., eds. New York: John wiley and Sons, Inc.

13. L_ Larry Gross, Michael Morgan, and Nancy Signorelli (1982), Charting the Mainstream - Television's Contributions to Political Orientations, Journal of Communications, 32 (2), 100-127.

14. Greenberg, A. and C. Suttoni (1973), Television Commercial Wearout, Journal of Advertising Research, 13 (6), 47-54.

15. Heitsmith, Glenn (1992), Lights Camera, Action, PROMO (October), 16.

16. Hovland, Carl I. and Irving L. Janis, eds. (1959), Personality and Persuasibility. New Haven, Ct: Yale University Press.

17. Kielwasser, Alfred and Michelle Wolf (1989), The Appeal of Soap Opera, Journal of Popular Culture, 23, (Fall), 111-21.

18. Krugman, Herbert E (1965), The Impact of Television Advertising: Learning without Involvement, Public Opinion Quarterly, 29 (Autumn), 349-56.

19. _ (1988), Point of View: Limits of Attention to Advertising, Journal of Advertising Research, 28 (October-November), 47-50.

20. Moore, Timothy (1982), Subliminal Advertising: What You See is What You Get, Journal of Marketing, 46 (Spring), 38-47.

21. Nielsen Co, A.C. (1987, 1992, 2002), Nielsen System Ratings, Northbrook, Ill.

22. Pollard, W.E. and Beck, V., Audience Analysis Research for Developing Entertainment-education Research: daytime dramas. Presented at the American Public Health Association, $128^{\text {th }}$ Annual Meeting, Boston, Mass.

23. Rice, Dorothy P., Economic Costs of Substance Abuse, 1995, Proceedings of the Association of American Physicians, 111(2): 119-125.

24. Rose, Brian (1979), Thickening the Plot, Journal of Communications, 29 (4), 81-84.

25. U.S. Department of Health and Human Services, A Comprehensive Plan for Preventing and Reducing Underage Drinking, Jan., 2006, p.18.

26. Wallack, Lawrence, Wallace Breed, and John Cruz (1987), Alcohol on Prime Time Television, Journal of Studies on Alcohol, 48 (1), 33-38. 